\title{
Prospective and longitudinal evolution of postoperative periprosthetic findings on metal artifact-reduced MR imaging in asymptomatic patients after uncemented total hip arthroplasty
}

\author{
Christoph Germann $^{1}$ (D) $\cdot$ Lukas Filli $^{1} \cdot$ Pia M. Jungmann ${ }^{1,2} \cdot$ Dimitri N. Graf $^{1} \cdot$ Jan Fritz $^{3} \cdot$ Christian W. A. Pfirrmann $^{1} \cdot$ \\ Reto Sutter ${ }^{1}$
}

Received: 14 August 2020 / Revised: 28 October 2020 / Accepted: 1 November 2020 / Published online: 9 November 2020

(C) The Author(s) 2020

\begin{abstract}
Objective To prospectively assess the evolution of postoperative MRI findings in asymptomatic patients after total hip arthroplasty (THA) over 24 months (mo).

Methods This prospective cohort study included 9 asymptomatic patients ( $56.7 \pm 15.0$ years) after THA. Metal artifact-reduced 1.5-T MRI was performed at 3, 6, 12, and 24 mo after surgery. The femoral stem and acetabular cup were assessed by two readers for bone marrow edema (BME), periprosthetic bone resorption, and periosteal edema in addition to periarticular soft tissue edema and joint effusion.

Results BME was common around the femoral stem in all Gruen zones after 3 mo (range: 50-100\%) and 6 mo (range: 33-100\%) and in the acetabulum in DeLee and Charnley zone II after 3 mo (100\%) and 6 mo (33\%). BME decreased substantially after 12 mo (range: 0-78\%) and 24 mo (range: 0-50\%), may however persist in particular in Gruen zones $1+7$. Periosteal edema along the stem was common 3 mo postoperatively (range: 63-75\%) and rare after 24 mo: 13\% only in Gruen zones 2 and 5. Twelve months and 24 mo postoperatively, periprosthetic bone resorption was occasionally present around the femoral stem (range: 11-33\% and 13-38\%, respectively). Soft tissue edema occurred exclusively along the surgical access route after 3 mo $(100 \%)$ and $6 \mathrm{mo}(89 \%)$ and never at $12 \mathrm{mo}$ or $24 \mathrm{mo}(0 \%)$.

Conclusion Around the femoral stem, BME (33-100\%) and periosteal edema (0-75\%) are common until 6 mo after THA, decreasing substantially in the following period, may however persist up to 24 mo (BME: 0-50\%; periosteal edema: 0-13\%) in few non-adjoining Gruen zones. Soft tissue edema along the surgical access route should have disappeared 12 mo after surgery.
\end{abstract}

Keywords Hip $\cdot$ Total hip arthroplasty $\cdot$ Magnetic resonance imaging $\cdot$ Bone $\cdot$ Normal postoperative findings

\section{Abbreviations}

BME Bone marrow edema

CS Compressed sensing

mo Months

SEMAC Slice encoding for metal artifact correction

Christoph Germann

christoph.germann@balgrist.ch

1 Radiology, Balgrist University Hospital, University of Zurich, Forchstrasse 340, CH-8008 Zurich, Switzerland

2 Department of Diagnostic and Interventional Radiology, Medical Center - University of Freiburg, Hugstetter Strasse 55,

79106 Freiburg, Germany

3 Department of Radiology, NYU Langone Health, 660 1st Ave, New York, NY 10016, USA
STIR Short $\tau$ inversion recovery

THA Total hip arthroplasty

WOMAC Western Ontario and McMaster Universities Arthritis Index

\section{Introduction}

The number of patients undergoing hip replacement surgery has drastically increased over the last decades [1]. Despite being one of the surgical procedures with the best outcome, complications such as aseptic loosening, periprosthetic fracture, hardware failure, wear-induced osteolysis/synovitis, and infection occur on a regular basis [2-4]. In order to improve patient outcomes, detecting these complications as early as possible is a major concern [5]. 
Radiographs represent the standard first-line imaging modality after total hip arthroplasty [6]. However, some alterations in the peri-implant region, e.g., in the periprosthetic bone marrow or soft tissues, may be the first signs indicating the abovementioned postoperative complications and cannot be depicted on radiographs [7].

Being the most accurate imaging modality to evaluate periprosthetic soft tissues, metal artifact-reduced MRI is of paramount importance to assess local complications after THA [2, 8-13]. Recently developed metal artifact reduction techniques such as Slice Encoding for Metal Artifact Correction (SEMAC) improve the detection of complications after THA [14-18] and advanced reconstruction techniques such as Compressed Sensing for SEMAC (CS-SEMAC) allow reducing the formerly long acquisition times [7, 19, 20]. These developments have sparked a new era in the visualization of the peri-implant region $[1,21]$.

However, the interpretation of MR images after THA remains challenging because there is substantial overlap between normal findings in asymptomatic patients and clinically relevant abnormal imaging findings. For example, periprosthetic bone marrow edema (BME) pattern - defined as the focal area of hyperintense intraosseous signal on fluidsensitive sequences $[22,23]$ - is frequently encountered in asymptomatic individuals 1 year after THA [24]. Other periimplant findings that are well depicted at MRI are (a) periprosthetic bone resorption, represented by a welldemarcated linear intraosseous band adjacent to the implant surface with high signal intensity on fluid-sensitive sequences, surrounded by a thin linear layer with low signal intensity [22]; (b) periosteal edema, defined as linear hyperintensity along the periosteum on fluid-sensitive sequences; and (c) periarticular soft tissue edema- depicted as a focal area of high signal intensity on fluid-sensitive sequences in the periprosthetic soft tissues (e.g., muscles). Thus far, there is no study available that addresses the chronological evolution of normal postoperative MR imaging findings after THA.

Therefore, the aim of this study was to prospectively evaluate the frequency of various MRI findings in the peri-implant region in asymptomatic patients following primary THA for a period of 24 months.

\section{Materials and methods}

\section{Study population}

This prospective single-center cohort study was approved by our local ethics committee. Written informed consent was given from all included subjects. Eleven of 175 potentially eligible consecutive patients agreed to participate in the study and were enrolled. Each of the potentially eligible patients underwent uncemented primary THA between April 2017 and October 2017 at our hospital. Inclusion criteria comprised: (a) age $\geq 18$ years, (b) Western Ontario and McMaster Universities Arthritis Index (WOMAC) score $\leq 1$ (considered asymptomatic) [25, 26], and (c) oral and written informed consent to participate in the study.

Exclusion criteria were as follows: (a) general contraindications for MRI (e.g., cardiac pacemaker) and (b) revision hip surgery or complex surgery (e.g., cerclage wires, acetabular reinforcement or bone grafting, cement and/or tumor prosthesis). The flowchart of patient inclusion and exclusion is presented in Fig. 1.

All prostheses were cementless systems with screwless acetabular cups and polyethylene inlays. The following implants were used: Versafitcup ${ }^{\circledR}$ and Quadra ${ }^{\circledR}$ system using a titanium-niobium alloy for the stem and a cobalt-chromium alloy for the femoral head ( $n=5$; Medacta); April Cup and SPS Evolution ${ }^{\circledR}$ Stem System using a titanium alloy for the stem and a cobalt-chromium alloy for the femoral head $(n=1$; SymBios); and Fitmore ${ }^{\circledR}$ using a titanium alloy for the femoral stem and either a ceramic head or a cobalt-chromium alloy for the head ( $n=3$; Zimmer Biomet). The surgical approach was

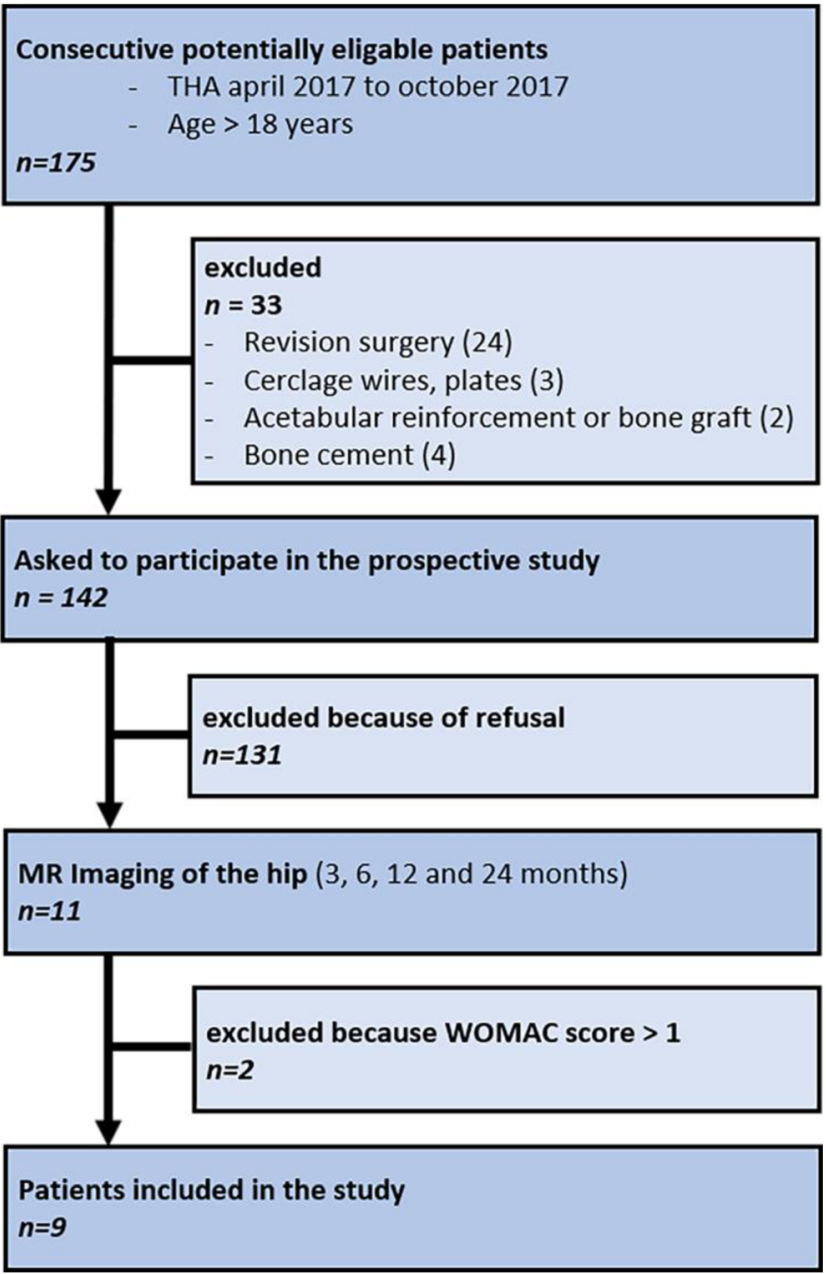

Fig. 1 Flowchart of patient inclusion and exclusion. THA, total hip arthroplasty; WOMAC, Western Ontario and McMaster Universities Arthritis Index questionnaire 
exclusively anterior; the capsulotomy was re-approximated and closed with dedicated sutures. Two board-certified hipsubspecialized orthopedic surgeons performed the procedure (surgeon 1 performed 3 of 9 arthroplasties and has 14 years of experience after board exam; surgeon 2 performed 6 of 9 arthroplasties with 6 years of experience after board exam). During the 24-month follow-up, none of the included subjects had revision hip surgery.

\section{Imaging}

Each patient had a total of 4 MRI scans of the respective hip joint during the first 2 years following hip replacement (3, 6, 12, and 24 months, respectively). All MR images were acquired with a 1.5-Tesla MAGNETOM Avanto Fit system (Siemens Healthcare, Erlangen, Germany), using a combination of an 18-channel surface coil and a 32-channel spine coil. The same clinical MRI protocol was used in all casesdedicated and optimized for metal artifact reduction around the hip implant. The protocol comprised a coronal STIR CSSEMAC sequence as part of a vendor-specific work-inprogress package (Siemens Healthcare), an axial short $\tau$ inversion recovery (STIR) sequence with optimized inversion pulse [27], and high-bandwidth sequences in all standard imaging planes. The CS-SEMAC sequence was applied with 19 slice-encoding steps (SES), 10 iterations, and a normalization factor of 0.001 to achieve optimal image quality. Detailed imaging parameters are listed in Table 1.

\section{MRI interpretation}

All MR images were evaluated separately by two board-certified musculoskeletal radiologists (C. G and D.G., with 6 and 7 years of experience, respectively). Image analysis was performed in an

Table 1 Detailed MRI protocol optimized for metal artifact reduction. $C S$, compressed sensing; ETL, echo train length; $F O V$, field of view; $N S A$, number of signal averages; SEMAC, slice encoding for metal independent and randomized fashion on anonymized data sets on a state-of-the-art picture archiving and communication system (Merlin, Phönix-PACS, Freiburg, Germany) workstation.

Each radiologist assessed the various Gruen zones and DeLee and Charnley zones $[28,29]$ with regard to the presence of periprosthetic bone marrow edema (BME) pattern, periprosthetic bone resorption, and periosteal edema using a binary scale (feature either present or absent). In order to be classified as a true finding, BME and periosteal edema had to be visualized in two imaging planes in the STIR sequences (axial and coronal) in the exact same location. We acknowledge the fact that in the radiological literature, the term "BME" is often used as a concise descriptive term on imaging, despite not being identical to the histopathologic diagnosis of bone marrow edema; however, in order to facilitate legibility of the manuscript, we use the term "BME" rather than "edema-like marrow signal intensity" or "bone marrow edema-like signal intensity" [30]. The presence of joint fluid was evaluated in a semiquantitative manner based on the maximum diameter of the fluid ("no to mild," $<3 \mathrm{~mm}$; "moderate," 3-6 mm; "substantial," >6 mm) in four directions relative to the prosthesis (lateral, medial, anterior, and posterior, respectively). Moreover, the integrity of the hip abductor tendons (gluteus medius and gluteus minimus) was evaluated as either "intact" or "torn": an intact tendon was defined as a homogenously low signal intensity continuous tendon without caliber irregularities in all sequences. Tendon discontinuity, intrasubstance high signal intensity on fluid-sensitive sequences, and/or fluid interposition between the tendon and osseous insertion were regarded as signs for a tendon tear.

\section{Statistical analysis}

Statistical analysis was performed using SPSS (v25, IBM Corp., Somers, NY). General descriptive statistics were

artifact correction; STIR, shirt $\tau$ inversion recovery; $T A$, acquisition time; $T E$, echo time; $T R$, repetition time. Axial STIR* with optimized inversion pulse

\begin{tabular}{|c|c|c|c|c|c|}
\hline Parameter & Coronal STIR SEMAC CS & Axial STIR* & Coronal T2 high bandwidth & $\begin{array}{l}\text { Axial T1 high } \\
\text { bandwidth }\end{array}$ & $\begin{array}{l}\text { Sagittal T1 high } \\
\text { bandwidth }\end{array}$ \\
\hline $\mathrm{TR} / \mathrm{TE}(\mathrm{ms})$ & $4220 / 36$ & $4000 / 31$ & $4000 / 58$ & $669 / 8.6$ & 6277.3 \\
\hline ETL & 9 & 11 & 15 & 3 & 3 \\
\hline NSA & 1 & 3 & 2 & 2 & 2 \\
\hline Number of slices & 25 & 27 & 20 & 29 & 31 \\
\hline Section thickness (mm) & 4 & 7 & 4 & 6 & 4 \\
\hline Spacing $(\mathrm{mm})$ & 4 & 8.75 & 6 & 8.4 & 4.4 \\
\hline Matrix & $256 \times 205$ & $384 \times 269$ & $512 \times 282$ & $512 \times 410$ & $320 \times 320$ \\
\hline FOV $\left(\mathrm{mm}^{2}\right)$ & $280 \times 280$ & $189 \times 189$ & $220 \times 220$ & $210 \times 210$ & $200 \times 200$ \\
\hline Bandwidth (Hz/pixel) & 500 & 450 & 390 & 425 & 435 \\
\hline Slice-encoding steps & 19 & - & - & - & - \\
\hline TA (min:s) & $06: 19$ & 03:56 & $02: 28$ & $02: 17$ & $01: 59$ \\
\hline
\end{tabular}


Fig. 2 Schematic illustration for the frequencies of bone marrow edema pattern: for each zone, the upper number represents results for reader 1 , the lower number for reader 2 . The frequencies are indicated by different color intensities (darker color equals higher percentage and vice versa) and listed as percentages. Bone marrow edema pattern was a frequent finding around the femoral stem both 3 mo (range: $50-100 \%$ ) and 6 mo (range: $33-$ $100 \%$ ) after THA, with a substantial decrease in the second postoperative year (12 mo range: $0-78 \%$; 24 mo range: $0-50 \%$ for reader 1 and $0-38 \%$ for reader 2 ). 24 mo after surgery, bone marrow edema pattern persisted most commonly in Gruen zones 1 and 7. mo, months

\section{bone marrow edema pattern}
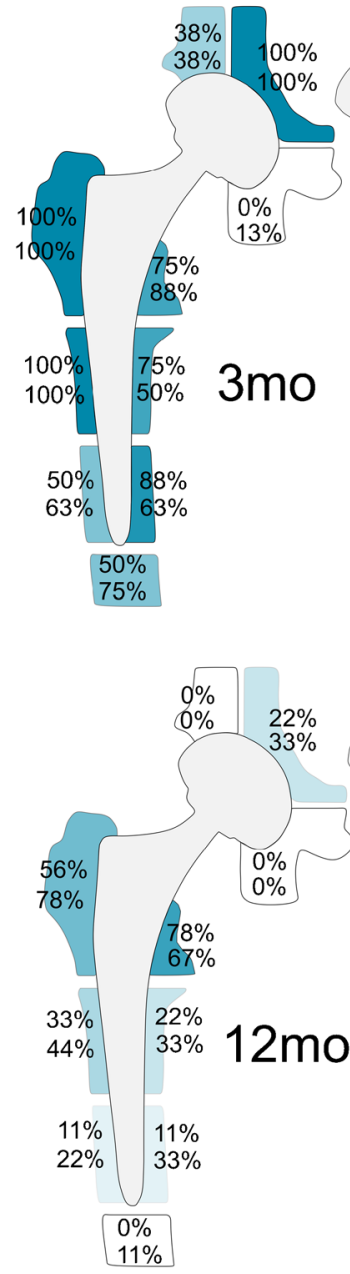
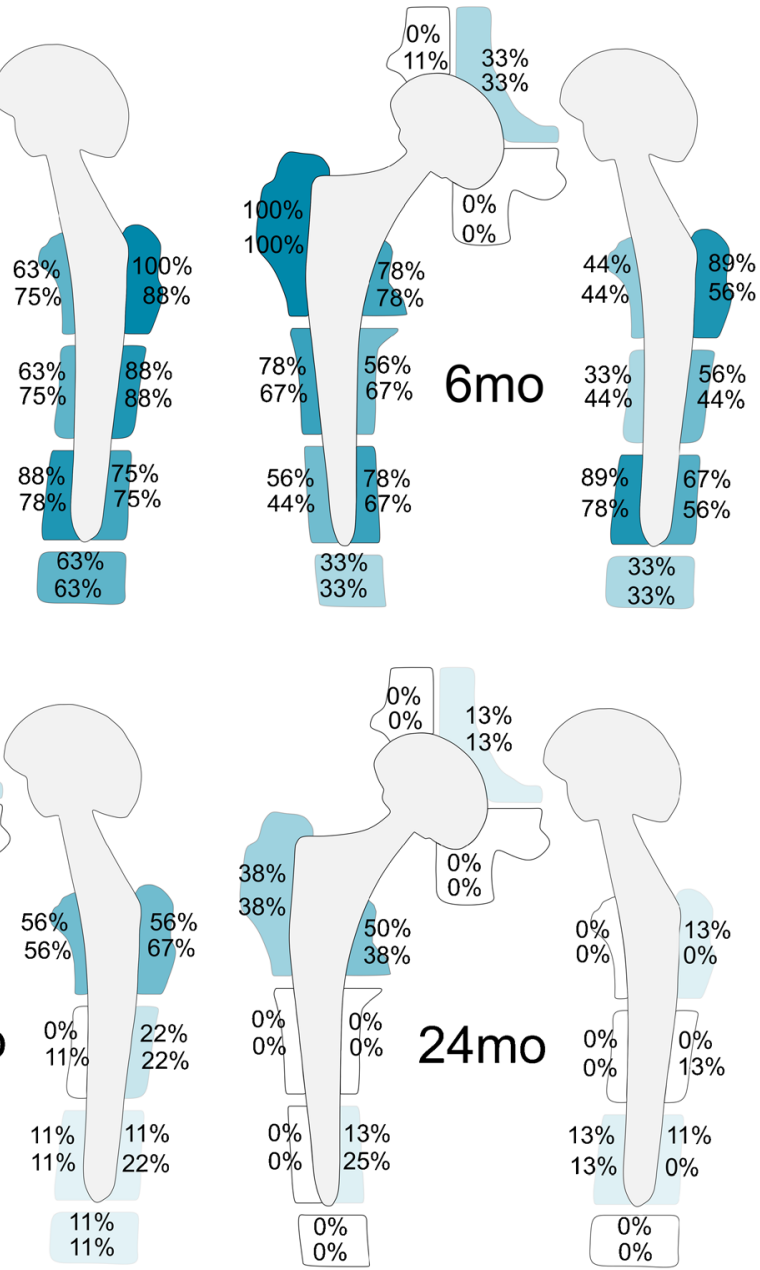

applied. The inter-reader agreement was determined by calculating Cohen's $\kappa$ for qualitative variables. Cohen's $\kappa$ was interpreted according to Kundel and Polansky as either "slight" (0-0.20), "fair" (0.21-0.40), "moderate" $(0.41-$ $0.60)$, "substantial" (0.61-0.80), or "almost perfect" agreement (0.81-1.00) [31]. Qualitative variables are presented as frequencies (percentages) for each time point.

\section{Results}

\section{Study population}

Eleven patients agreed to participate in the study ( 6 males, 5 females; mean age: $56.6 \pm 14.8$ years, range $22-70$ years). Each subject had a total of 4 MRI scans during the 2 first years after THA: 3, 6, 12, and 24 months, respectively. All MRI examinations were completed successfully. After excluding every patient with a WOMAC score $>1$ at each study visit
( 2 patients with a consecutive WOMAC score $>1$ at each time point, respectively), a total of 9 patients were included (4 males, 5 females; mean age, $56.7 \pm 15.0$ years; age range 22-70 years). Due to missing data (no WOMAC score), one additional patient was excluded for the 3-month and 24-month MRI scan, respectively. WOMAC scores were as follows: 4.8 \pm 1.5 (range 2.6-6.7) preoperatively; $0.6 \pm 0.4$ (range $0.0-1.0$ ) at 3 months; $0.3 \pm 0.4$ (range $0.0-1.0$ ) at 6 months; $0.3 \pm 0.4$ (range $0.0-1.0$ ) at 12 months; and $0.2 \pm 0.2$ (range $0.0-0.5$ ) at 24 months, respectively. Two of nine included patients (22\%) were diagnosed with secondary osteoarthritis (one caused by femoroacetabular impingement, one by developmental dysplasia of the hip); the remaining seven of nine included patients $(78 \%)$ were diagnosed with primary osteoarthritis.

\section{Inter-observer agreement}

Inter-observer agreement was "substantial" for bone marrow edema pattern $(\kappa=0.71)$, periosteal edema $(\kappa=0.80)$, and joint fluid $(\kappa=0.75)$, and "almost perfect" for periprosthetic 
bone resorption $(\kappa=0.93)$ as well as periarticular soft tissue edema $(\kappa=0.91)$.

\section{Frequency of MRI findings}

Detailed results and graphical illustrations for all Gruen zones and DeLee and Charnley zones regarding BME pattern, periprosthetic bone resorption, and periosteal edema are presented in Figs. 2, 3, and 4, respectively (reader 1).

\section{Bone marrow edema}

BME pattern was a common finding around the femoral stem 3 and 6 months after surgery, most frequently in Gruen zones $1,2,5,6,7,10,12,13$, and 14 (3 months: range $75-100 \%$ for reader 1 and $63-100 \%$ for reader $2 ; 6$ months: range $56-100 \%$ for reader 1 and $44-100 \%$ for reader 2). BME adjacent to the acetabular cup was present consistently after 3 months in
DeLee and Charnley zone II for both readers (100\%, respectively). In general, the extent of BME pattern decreased substantially with time after surgery; 12 months: range $0-78 \%$ for both readers; and 24 months: range $0-56 \%$ for reader 1 and range $0-38 \%$ for reader 2 . BME persisted up to 24 months in various areas around the femoral stem, in particular in Gruen zones 1 and 7 (38\% and 50\%, respectively for reader $1 ; 38 \%$ and $38 \%$, respectively for reader 2) (Fig. 5), whereas BME disappeared completely after 24 months in Gruen zones 2, 3, $4,6,8,9,11$, and 12 ( $0 \%$ for both readers). Furthermore, there was no BME after 24 months in DeLee and Charnley zones I and III ( $0 \%$ for both readers).

\section{Periprosthetic bone resorption}

For both readers, periprosthetic bone resorption was present most commonly in Gruen zones 1 and 8 after 12 and 24 months: Gruen zone 1 for both readers: 33\% after
Fig. 3 Schematic illustration for the frequencies of periprosthetic bone resorption: for each zone, the upper number represents results for reader 1 , the lower number for reader 2 . The frequencies are indicated by different color intensities (darker color equals higher percentage and vice versa) and listed as percentages. Periprosthetic bone resorption was most commonly encountered in Gruen zones 1 and 8 , starting already 6 mo after THA in one participant $(11 \%)$. Over time, there was a slight increase in periprosthetic bone resorption around the femoral stem (12 mo range: $0-33 \% ; 24$ mo range: $0-$ $38 \%$ ). mo, months; THA, total hip arthroplasty

\section{periprosthetic bone resorption}
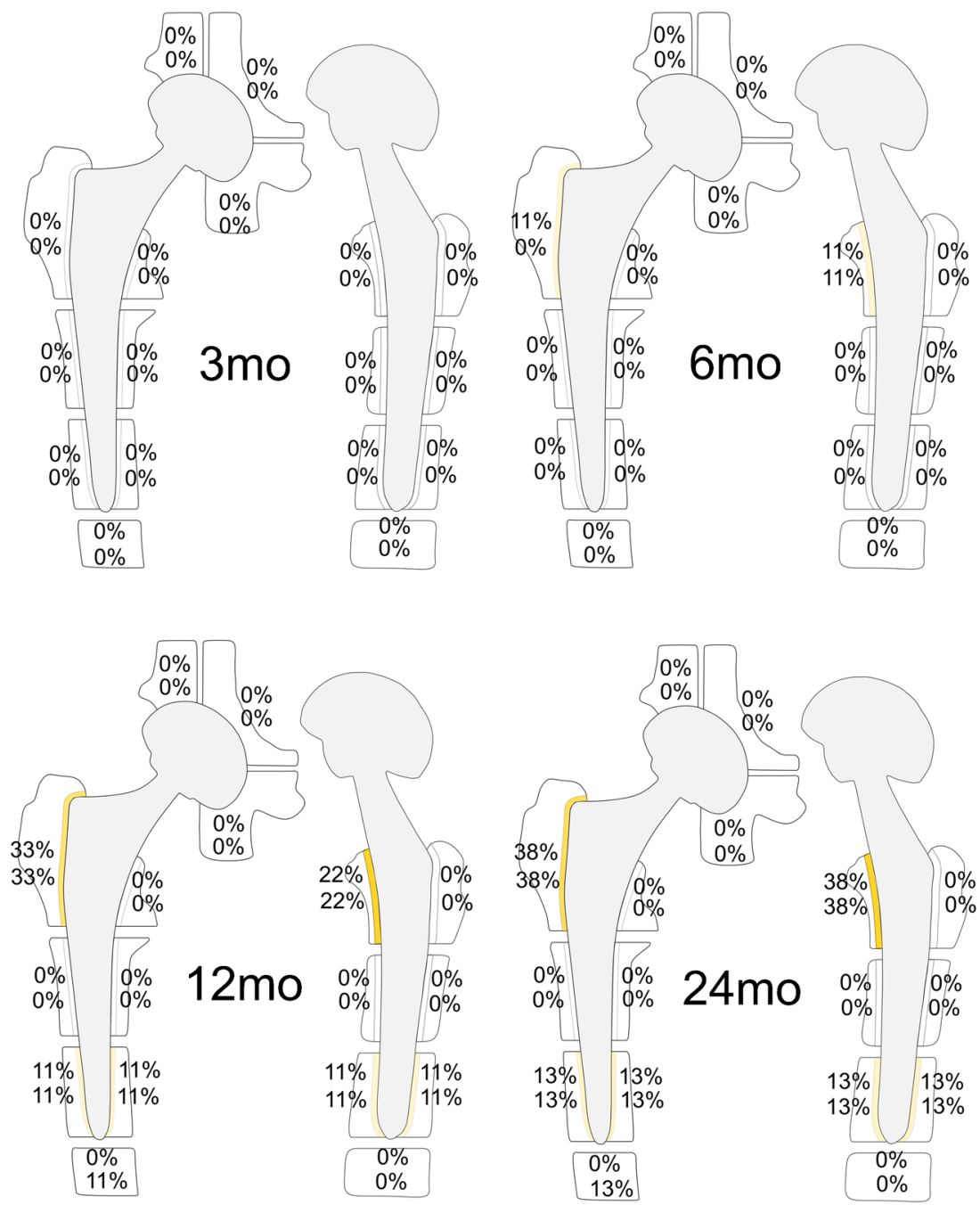
Fig. 4 Schematic illustration for the frequencies of periosteal edema: for each zone, the upper number represents results for reader 1 , the lower number for reader 2 . The frequencies are indicated by different color intensities (darker color equals higher percentage and vice versa) and listed as percentages.

Periosteal edema was a frequent finding around the femoral stem 3 mo after THA (range: 0-75\% for reader 1 and $0-88 \%$ for reader 2 ), accentuated in Gruen zones 2 , 3,6 , and 9. Over time, there was a substantial decrease around the femoral stem (12 mo range: 0 $22 \%$; 24 mo range: $0-13 \%$ ) 24 mo after surgery periosteal edema persisted only in one patient in Gruen zones 2, 5, and 10 , respectively. mo, months; $T H A$, total hip arthroplasty

\section{periosteal edema}
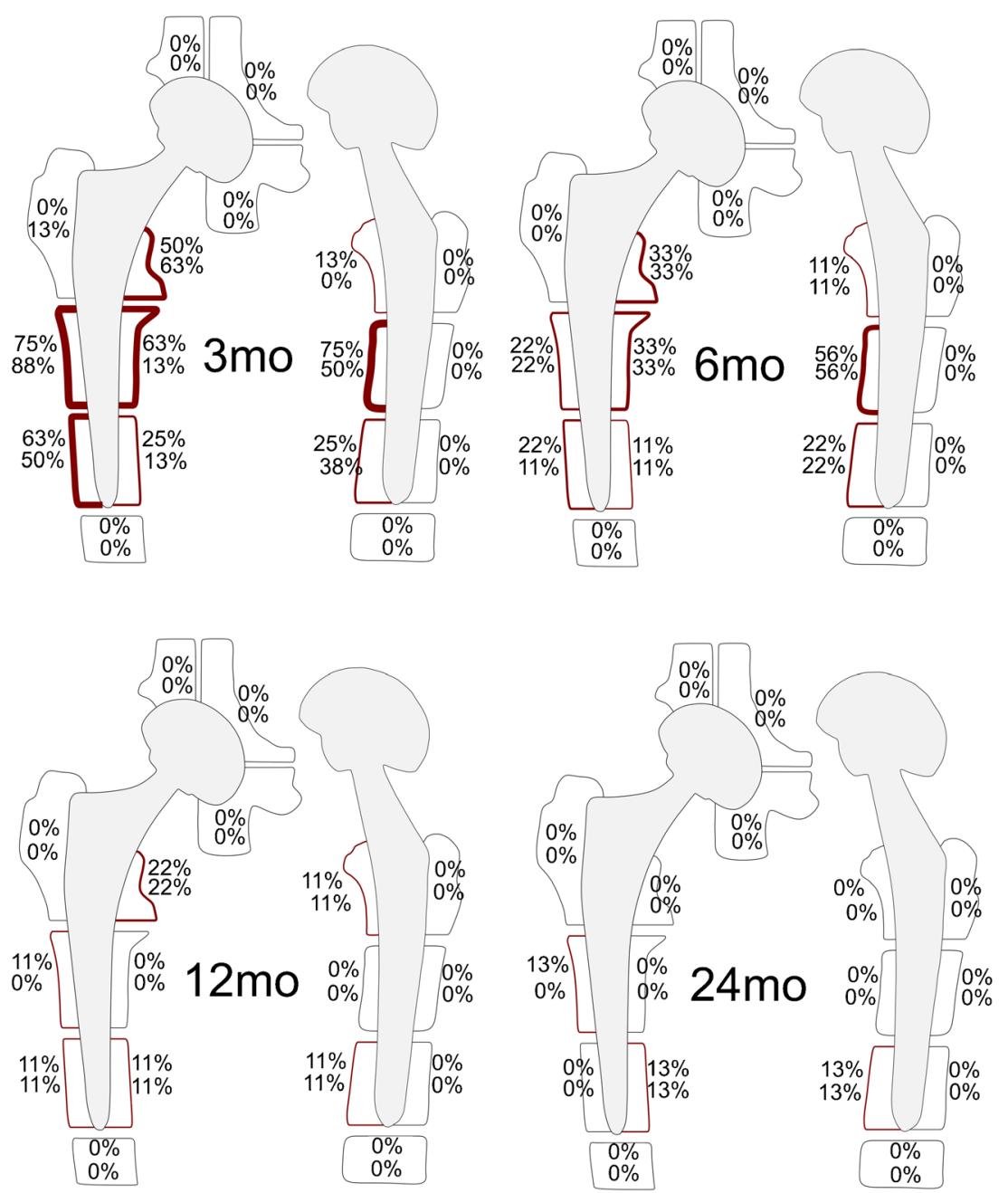

12 months and 38\% after 24 months, and Gruen zone 8 for both readers: $22 \%$ after 12 months and $38 \%$ after 24 months. Reader 1 described periprosthetic bone resorption in Gruen zones 1 and 8 for one patient (11\%) already 6 months after surgery (Fig. 6). Both readers described periprosthetic bone resorption for one patient in Gruen zones 3, 5, 10, and 12 after 12 months (11\%) and 24 months (13\%), respectively. Additionally, reader 2 found periprosthetic bone resorption present in Gruen zone 4 in one patient after 12 months (11\%) and 24 months (13\%), respectively. The maximum width of the periprosthetic bone resorption was $2 \mathrm{~mm}$.

\section{Periosteal edema}

Three months after surgery, periosteal edema was frequently seen in Gruen zone 2 (75\% for reader $1 ; 88 \%$ for reader 2 ), Gruen zone 3 (63\% for reader $1 ; 50 \%$ for reader 2), Gruen zone 6 (63\% for reader $1 ; 50 \%$ for reader 2$)$, Gruen zone 7 (50\% for reader $1 ; 63 \%$ for reader 2), and Gruen zone $9(75 \%$ for reader $1 ; 50 \%$ for reader 2 ). Over time, there was a substantial decrease in periosteal edema around the femoral shaft: 24 months after the surgery, periosteal edema persisted only in 1 patient in Gruen zones 5 and 10 (13\%, respectively for both readers) as well as in Gruen zone 2 (13\% for reader 1) (Fig. 7). Never was any periosteal edema present adjacent to the acetabular cup.

\section{Periarticular soft tissue edema}

Periarticular soft tissue edema in the surgical access route (anterior) was present in all patients 3 months after surgery (100\% for both readers) and almost all participants after 6 months ( $89 \%$ for reader $1 ; 100 \%$ for reader 2 ). No soft tissue edema in any location occurred after 12 or 24 months (Fig. 8).

\section{Joint fluid}

Detailed results regarding the location and quantity of joint fluid for both readers are listed in Table 2. After 3 months, several patients showed moderate to substantial amounts of 

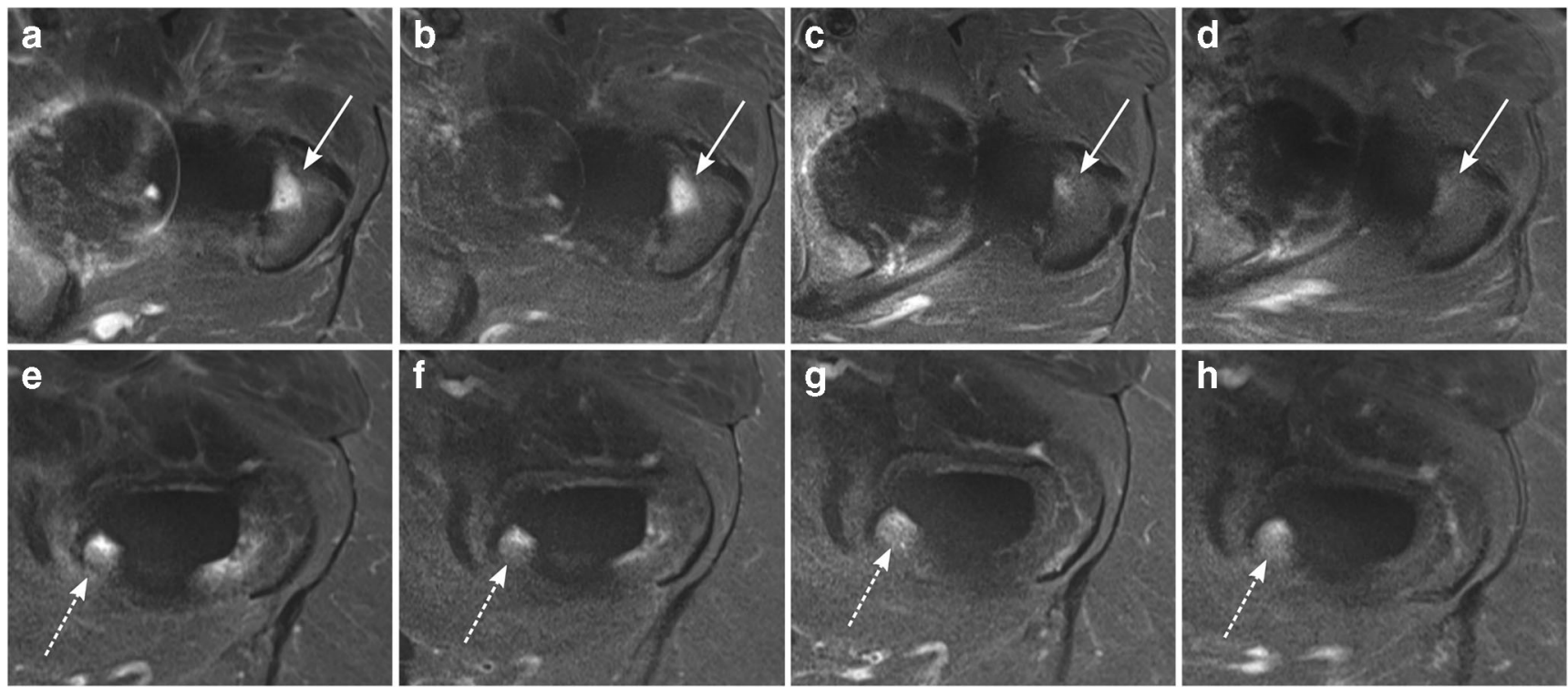

Fig. 5 BME around the femoral stem on axial STIR MRI. A 68-year-old asymptomatic woman with left-sided THA and BME pattern around the femoral stem in Gruen zone 1 (arrows) decreasing over time $(\mathbf{a}=$ 3 months, $\mathbf{b}=6$ months, $\mathbf{c}=12$ months, and $\mathbf{d}=24$ months after THA).

Persisting BME in the same patient in Gruen zone 7 (dashed arrows; $\mathbf{e}=$ 3 months, $\mathbf{f}=6$ months, $\mathbf{g}=12$ months, and $\mathbf{h}=24$ months after THA). $B M E$, bone marrow edema; THA, total hip arthroplasty

joint fluid in the anterior $(25 \% \geq 3 \mathrm{~mm}$ for reader $1 ; 37.5 \% \geq$ $3 \mathrm{~mm}$ for reader 2$)$, medial ( $50 \% \geq 3 \mathrm{~mm}$ for both readers), and lateral location $(62.5 \% \geq 3 \mathrm{~mm}$ for both readers), whereas

no to mild joint effusion was present posteriorly during the whole follow-up period $(100 \%<3 \mathrm{~mm}$ for reader $1 ; 88-100 \%$ $<3 \mathrm{~mm}$ for reader 2) (Fig. 9). The amount of joint fluid in the
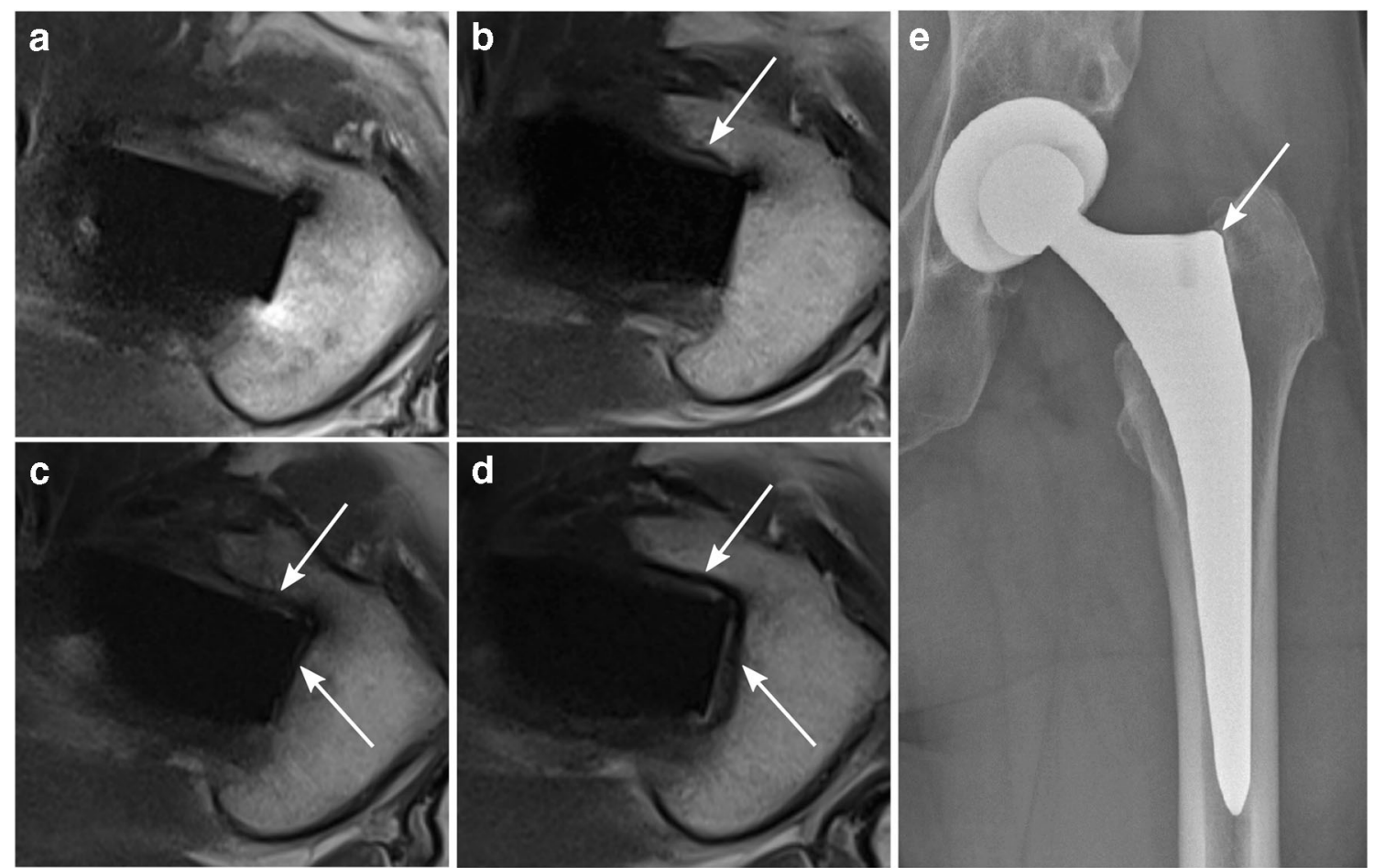

Fig. 6 Periprosthetic bone resorption on axial T1w MRI. A 52-year-old asymptomatic woman with left-sided THA. A well-demarcated periprosthetic resorption zone (maximum width $2 \mathrm{~mm}$ ) with a hypointense peripheral lining (arrows) is present laterally along the proximal femoral shaft (Gruen zone 1) 12 months (c) and 24 months (d) after surgery with no correlate 3 months (a) and 6 months (b) postoperatively.

Additionally, a small resorption zone can be seen anteriorly along the proximal femoral shaft in Gruen zone 8 after 6, 12, and 24 months (bd) without a definite correlate as early as 3 months (a). AP radiographic correlation 12 months after surgery (e) shows a demarcated narrow osteolytic zone in Gruen zone 1. THA, total hip arthroplasty 

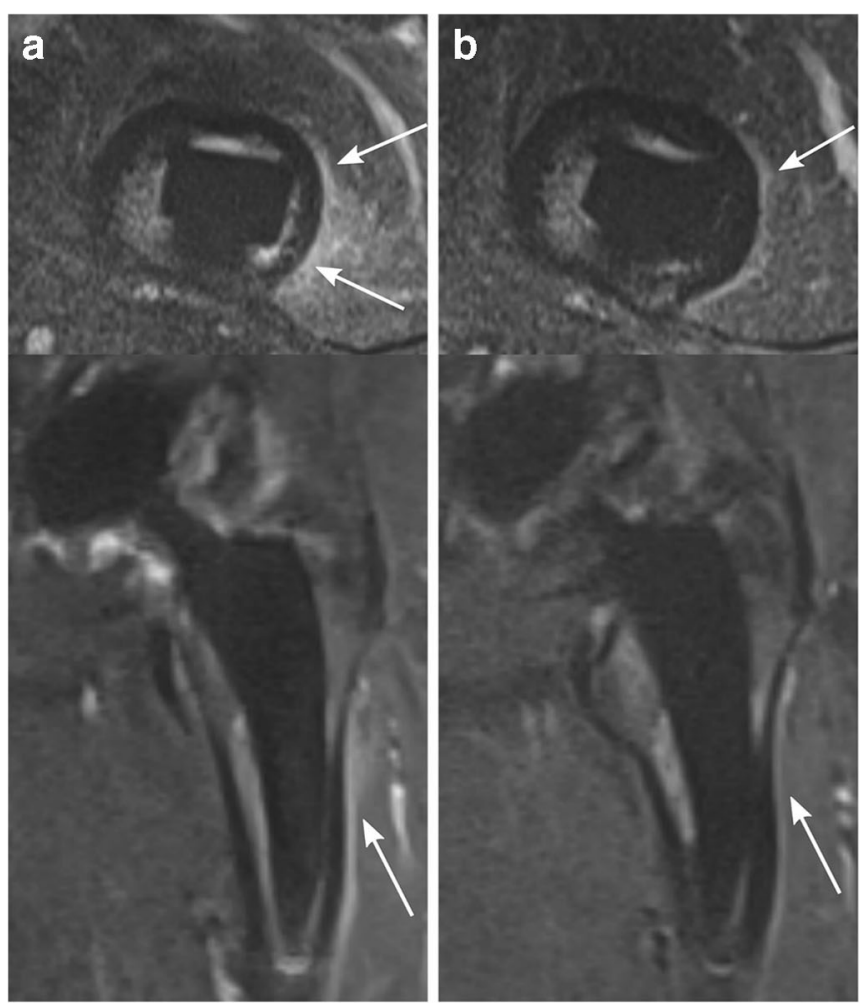

Fig. 7 Periosteal edema on axial STIR MRI (upper row) and coronal STIR CS-SEMAC MRI (lower row). A 60-year-old asymptomatic woman with left-sided THA. Periosteal edema is present along the lateral side of the femoral shaft, accentuated in Gruen zone 2 (arrows),

anterior, medial, and lateral location decreased gradually from 3 to 24 months after THA, showing no to only mild joint effusion after 24 months in the majority of patients anteriorly and medially $(100 \%<3 \mathrm{~mm}$ for reader $1 ; 88-100 \%<3 \mathrm{~mm}$ for reader 2$)$ as well as laterally $(75 \%<3 \mathrm{~mm}$ for reader 1 ; $62.5 \%<3 \mathrm{~mm}$ for reader 2 ).

\section{Gluteal tendons}

Both the gluteus medius and minimus tendon were intact in nine of nine patients (100\%) during the 24-month follow-up.

\section{Other findings}

No extraarticular fluid collection was present at any time.

\section{Discussion}

The purpose of this prospective longitudinal study was to show the natural evolution of normal periprosthetic MRI findings in the first 2 years after THA in asymptomatic individuals. To our knowledge, this is the first prospective study in the scientific literature to address this issue.
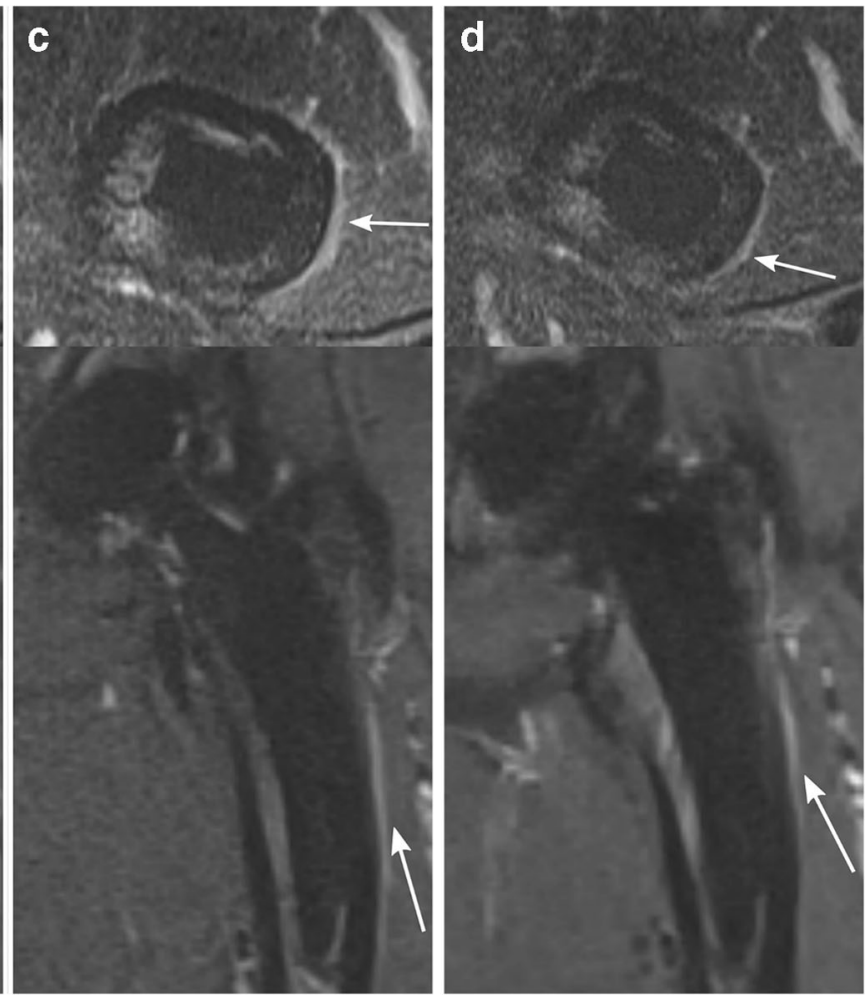

which persists over time. $\mathbf{a}=3$ months, $\mathbf{b}=6$ months, $\mathbf{c}=12$ months, and d $=24$ months. $C S$, compressed sensing; SEMAC, slice encoding for metal artifact correction; THA, total hip arthroplasty

BME after THA may occur due not only to intraoperative reaming and compaction techniques but also from pathologic conditions such as mechanical stress reaction, implant loosening, or infection [13, 22, 24, 32, 33]. Compared to a retrospective cross-sectional study [24], our prospective study gives incremental insight regarding the evolution of BME over time. In our cohort, BME occurred frequently and diffusely around the femoral stem as well as centrally at the acetabular cup 3 and 6 months after surgery. There was a substantial decrease in BME over time, persisting up to 24 months after THA around the upper lateral and medial femoral stem (Gruen zones 1 and 7) in some cases. This persistent BME up to 24 months after surgery in asymptomatic individuals can be a possible pitfall in MRI interpretation and should not be overcalled as unequivocal pathology, in particular, if it affects only single and non-adjoining Gruen zones. Importantly, $\mathrm{BME}$ at the inferomedial portion of the cup rarely occurred 3 months after surgery and never later than that, so any BME seen at this location 6 months or longer after surgery is suspicious of pathology.

Uncemented THA are designed with roughened or coated surfaces to facilitate osseous ingrowth [3]. However, a frequent finding in uncemented THA is the development of a fibrous membrane which can be considered a meta-stable status and should be followed for progression to implant 
Fig. 8 Periarticular soft tissue edema on axial STIR MRI. A 70year-old asymptomatic woman with left-sided THA. Soft tissue edema (arrows) is present anteriorly along the surgical access route 3 months (a) and 6 months (b) after THA, which completely disappeared 12 months (c) and 24 months (d) after THA. THA, total hip arthroplasty
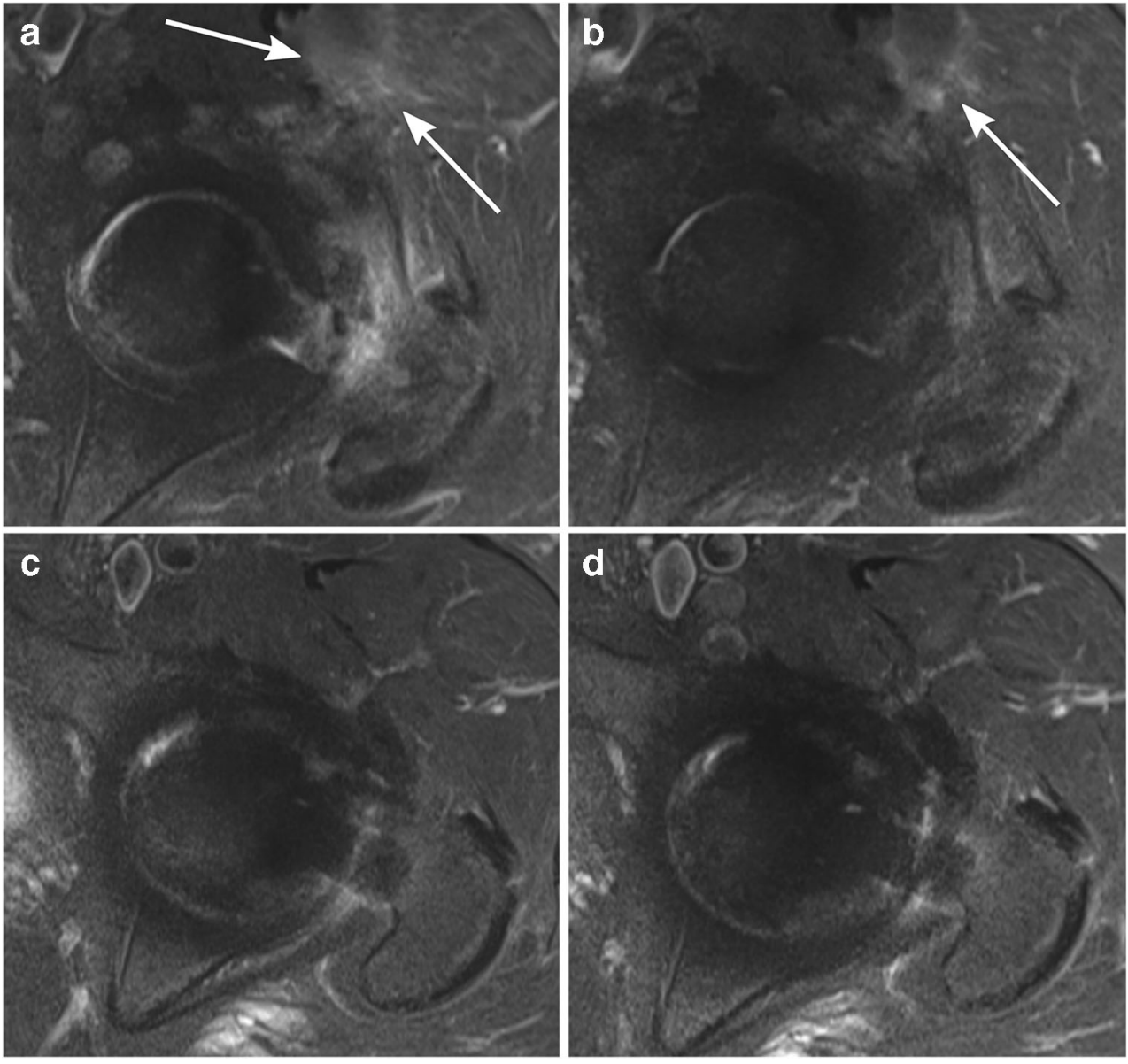

loosening $[1,6,22,34]$. We defined " periprosthetic bone resorption" as a well-demarcated linear band between the implant surface and the host bone, independent of its thickness [24]. This feature was occasionally seen adjacent to the lateral and anterior shoulder of the femoral stem (Gruen zones 1 and
8) in the second postoperative year; however, the maximum width was $2 \mathrm{~mm}$, which should not be considered a sign of loosening [1].

Periosteal edema can be a manifestation of osseous stress reaction or periprosthetic infection $[1,22]$. However, it has
Table 2 Amount of joint fluid, measured as the distance between the prosthetic head/neck and the joint capsule in 4 directions. For both readers, joint fluid was pronounced in the medial and lateral aspects. Over time, there was a slight decrease with persistent substantial joint fluid $(>6 \mathrm{~mm}$ ) only in few patients in the lateral aspect after 12 and 24 months. ant., anterior; post., posterior; med., medial; lat., lateral; mo, months

\begin{tabular}{|c|c|c|c|c|c|c|c|c|c|}
\hline \multicolumn{2}{|c|}{ Joint fluid } & \multicolumn{4}{|c|}{ Reader 1} & \multicolumn{4}{|c|}{ Reader 2} \\
\hline & & $\begin{array}{l}3 \mathrm{mo} \\
(\%)\end{array}$ & $\begin{array}{l}6 \mathrm{mo} \\
(\%)\end{array}$ & $\begin{array}{l}12 \mathrm{mo} \\
(\%)\end{array}$ & $\begin{array}{l}24 \mathrm{mo} \\
(\%)\end{array}$ & $\begin{array}{l}3 \mathrm{mo} \\
(\%)\end{array}$ & $\begin{array}{l}6 \mathrm{mo} \\
(\%)\end{array}$ & $\begin{array}{l}12 \mathrm{mo} \\
(\%)\end{array}$ & $\begin{array}{l}24 \mathrm{mo} \\
(\%)\end{array}$ \\
\hline \multirow[t]{3}{*}{ ant. } & $<3 \mathrm{~mm}$ & 75 & 89 & 100 & 100 & 62.5 & 89 & 100 & 100 \\
\hline & $3-6 \mathrm{~mm}$ & 12.5 & 11 & 0 & 0 & 12.5 & 11 & 0 & 0 \\
\hline & $>6 \mathrm{~mm}$ & 12.5 & 0 & 0 & 0 & 25 & 0 & 0 & 0 \\
\hline \multirow[t]{3}{*}{ post. } & $<3 \mathrm{~mm}$ & 100 & 100 & 100 & 100 & 87.5 & 100 & 100 & 100 \\
\hline & $3-6 \mathrm{~mm}$ & 0 & 0 & 0 & 0 & 12.5 & 0 & 0 & 0 \\
\hline & $>6 \mathrm{~mm}$ & 0 & 0 & 0 & 0 & 0 & 0 & 0 & 0 \\
\hline \multirow[t]{3}{*}{ med. } & $<3 \mathrm{~mm}$ & 50 & 67 & 100 & 100 & 50 & 67 & 100 & 88 \\
\hline & $3-6 \mathrm{~mm}$ & 25 & 22 & 0 & 0 & 25 & 22 & 0 & 12 \\
\hline & $>6 \mathrm{~mm}$ & 25 & 11 & 0 & 0 & 25 & 11 & 0 & 0 \\
\hline \multirow[t]{3}{*}{ lat. } & $<3 \mathrm{~mm}$ & 37.5 & 78 & 78 & 75 & 37.5 & 78 & 56 & 62.5 \\
\hline & $3-6 \mathrm{~mm}$ & 50 & 11 & 11 & 12.5 & 50 & 11 & 22 & 25 \\
\hline & $>6 \mathrm{~mm}$ & 12.5 & 11 & 11 & 12.5 & 12.5 & 11 & 22 & 12.5 \\
\hline
\end{tabular}




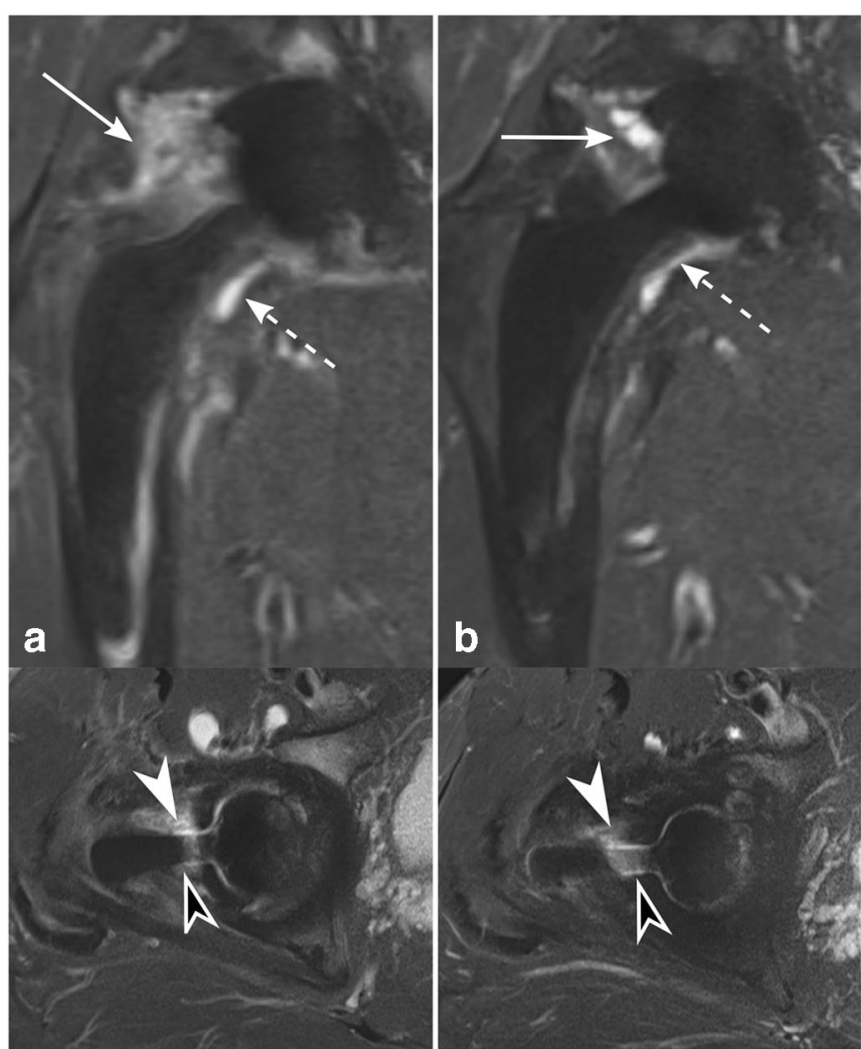

Fig. 9 Joint effusion on coronal STIR CS-SEMAC (upper row) and on axial STIR (lower row) during the first two postoperative years $(\mathbf{a}=$ 3 months, $\mathbf{b}=6$ months, $\mathbf{c}=12$ months, and $\mathbf{d}=24$ months). A 51year-old asymptomatic man with right-sided THA. Persisting joint effusion is clearly present laterally (arrows) with a maximum width of

been shown that periosteal edema may occur in asymptomatic individuals 12 months after THA, although less commonly than in symptomatic individuals [24]. Beyond that, our data illustrate the chronological evolution of periosteal edema, being very common 3 months after surgery in the anterior, lateral, and medial femoral shaft with a gradual decrease over the first 2 postoperative years, rarely persisting up to 24 months. Interestingly, periosteal edema-similar to the BME pattern-only occurred in non-adjacent Gruen zones after 24 months. There was no periosteal edema at the acetabulum, which may be attributed to the difference in force transmission between the femoral and acetabular side during hip arthroplasty - in particular using an anterior approach, which may put more mechanical stress on the femoral shaft $[35,36]$, therefore potentially causing longer persistent periosteal edema.

Periarticular soft tissue edema is a non-specific finding. For example, it may indicate a periprosthetic infection [22]. Our data imply that soft tissue edema in the surgical access route is a constant feature in the first 6 months, but never occurred in the second postoperative year.

Joint effusion is also a non-specific finding, caused e.g. by periprosthetic infection or wear-induced synovitis $[1,22]$ but

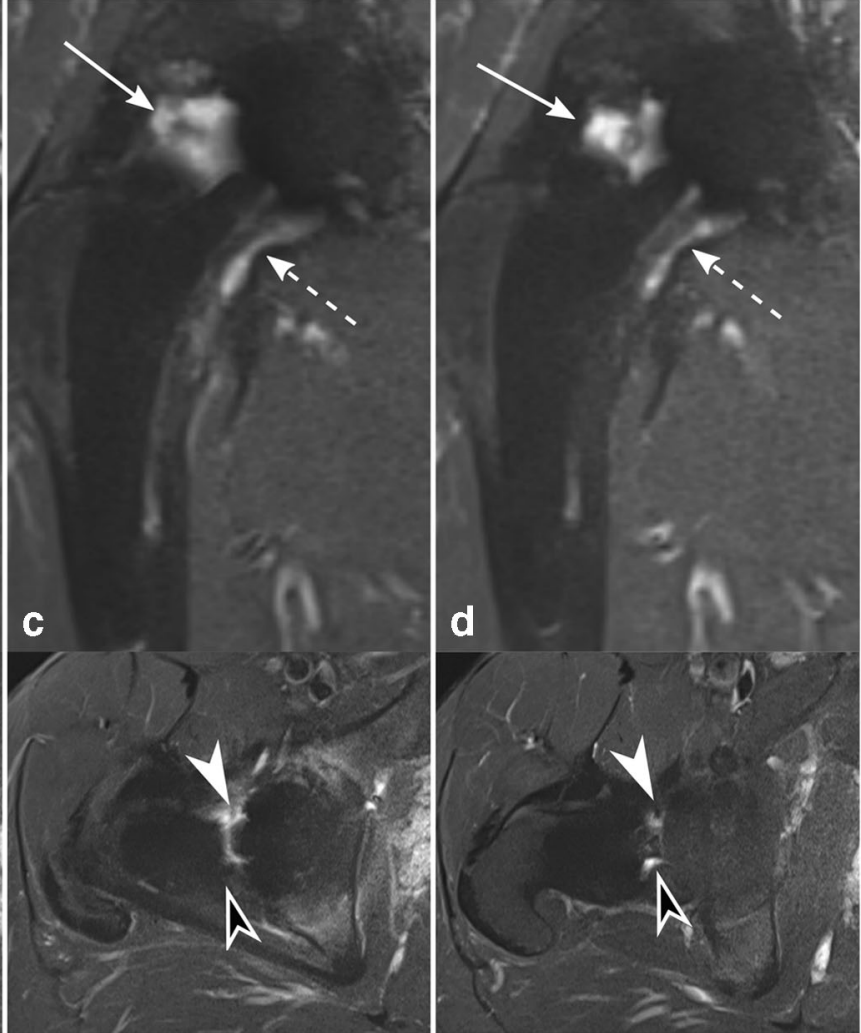

$>6 \mathrm{~mm}$, whereas only a small amount of joint fluid $(<3 \mathrm{~mm})$ is seen medially (dashed arrows). Anteriorly (white arrowhead) and posteriorly (black arrowhead), no clear joint effusion can be identified. $C S$, compressed sensing; SEMAC, slice encoding for metal artifact correction; THA, total hip arthroplasty

may also be seen in asymptomatic individuals [24]. We found substantial joint effusion most commonly in the medial and lateral aspect 3 months after THA, decreasing with time after surgery. However, substantial joint effusion may be seen as late as 24 months after surgery in some asymptomatic individuals in the lateral aspect and therefore, these imaging findings imply careful interpretation. During the 24-month followup, both the gluteus medius and minimus tendons were intact in all patients, as can be expected when using an anterior surgical approach, accessing the hip joint between the rectus femoris and tensor fasciae latae muscle.

There are limitations to our study. First, the small cohort size ( $n=9$ patients) may limit the generalizability of our findings. However, four consecutive MRI examinations were available for each included subject and substantial to almost perfect inter-reader agreement represents plausible validity of the detected imaging findings. Second, this study was limited to primary uncemented THA with three different titaniumbased systems. Therefore, our observations may not apply to other scenarios such as complex surgeries, revision surgeries, or cemented prostheses. Third, bone quality was not systematically documented, but may potentially affect the MRI findings in the periprosthetic bone after hip arthroplasty. Despite 
these limitations, we strongly believe that our data may serve as a standard reference regarding the evolution of normal postoperative MRI findings, which is crucial to be aware of in order to correctly evaluate postoperative complications and not to misinterpret actual normal findings.

In conclusion, BME and periosteal edema along the femoral stem are a frequent finding in asymptomatic patients within the first 6 months after THA, decreasing substantially in the following period. However, BME and periosteal edema may persist in a few non-adjoining Gruen zones in a few asymptomatic individuals up to 24 months and should not be mistaken as unequivocal pathology. The occurrence of periarticular soft tissue edema as late as 12 months after surgery should be considered an abnormal finding and necessitates further diagnostic workup, e.g., to exclude periprosthetic infection. A thin $(\leq 2 \mathrm{~mm})$ linear well-demarcated osseous resorption adjacent to the proximal and to a lesser degree adjacent to the distal femoral stem can be seen in the second postoperative year after THA in asymptomatic patients.

Funding Open access funding provided by University of Zurich.

\section{Compliance with ethical standards}

This prospective single-center cohort study was approved by our local ethics committee. Written informed consent was given from all included subjects.

Conflict of interest Jan Fritz received institutional research support from Siemens Healthcare USA, DePuy, Zimmer, Microsoft, and BTG International; is a scientific advisor of Siemens Healthcare USA and GE Healthcare Technologies and BTG International; and has shared patents with Siemens Healthcare and Johns Hopkins University. However, this study was not sponsored by any of these companies.

The other authors declare that they have no conflict of interest.

Open Access This article is licensed under a Creative Commons Attribution 4.0 International License, which permits use, sharing, adaptation, distribution and reproduction in any medium or format, as long as you give appropriate credit to the original author(s) and the source, provide a link to the Creative Commons licence, and indicate if changes were made. The images or other third party material in this article are included in the article's Creative Commons licence, unless indicated otherwise in a credit line to the material. If material is not included in the article's Creative Commons licence and your intended use is not permitted by statutory regulation or exceeds the permitted use, you will need to obtain permission directly from the copyright holder. To view a copy of this licence, visit http://creativecommons.org/licenses/by/4.0/.

\section{References}

1. Khodarahmi I, Fritz J. Advanced MR imaging after total hip arthroplasty: the clinical impact. Semin Musculoskelet Radiol. 2017;21(5):616-29.

2. White LM, Kim JK, Mehta M, Merchant N, Schweitzer ME, Morrison WB, et al. Complications of total hip arthroplasty: MR imaging-initial experience. Radiology. 2000;215(1):254-62.
3. Roth TD, Maertz NA, Parr JA, Buckwalter KA, Choplin RH. CT of the hip prosthesis: appearance of components, fixation, and complications. Radiographics. 2012;32(4):1089-107.

4. Mulcahy H, Chew FS. Current concepts of hip arthroplasty for radiologists: part 2, revisions and complications. AJR Am J Roentgenol. 2012;199(3):570-80.

5. Hayter CL, Koff MF, Potter HG. Magnetic resonance imaging of the postoperative hip. J Magn Reson Imaging. 2012;35(5):101325 .

6. Chang CY, Huang AJ, Palmer WE. Radiographic evaluation of hip implants. Semin Musculoskelet Radiol. 2015;19(1):12-20.

7. Otazo R, Nittka M, Bruno M, Raithel E, Geppert C, Gyftopoulos S, et al. Sparse-SEMAC: rapid and improved SEMAC metal implant imaging using SPARSE-SENSE acceleration. Magn Reson Med. 2017;78(1):79-87.

8. Potter HG, Foo LF. Magnetic resonance imaging of joint arthroplasty. The Orthopedic clinics of North America. 2006;37(3):361-73 vi-vii.

9. Weiland DE, Walde TA, Leung SB, Sychterz CJ, Ho S, Engh CA, et al. Magnetic resonance imaging in the evaluation of periprosthetic acetabular osteolysis: a cadaveric study. Journal of orthopaedic research : official publication of the Orthopaedic Research Society. 2005;23(4):713-9.

10. Walde TA, Weiland DE, Leung SB, Kitamura N, Sychterz CJ, Engh CA Jr, et al. Comparison of CT, MRI, and radiographs in assessing pelvic osteolysis: a cadaveric study. Clin Orthop Relat Res. 2005;437:138-44.

11. Pfirrmann CW, Notzli HP, Dora C, Hodler J, Zanetti M. Abductor tendons and muscles assessed at MR imaging after total hip arthroplasty in asymptomatic and symptomatic patients. Radiology. 2005;235(3):969-76.

12. Potter HG, Nestor BJ, Sofka CM, Ho ST, Peters LE, Salvati EA. Magnetic resonance imaging after total hip arthroplasty. The Journal of Bone and Joint Surgery-American Volume. 2004;86(9):1947-54.

13. Galley J, Sutter R, Stern C, Filli L, Rahm S, Pfirmann CWA. Diagnosis of periprosthetic hip joint infection using MRI with metal artifact reduction at 1.5 T. Radiology. 2020;296(1):98-108.

14. Lu W, Pauly KB, Gold GE, Pauly JM, Hargreaves BA. SEMAC: slice encoding for metal artifact correction in MRI. Magn Reson Med. 2009;62(1):66-76.

15. Sutter R, Ulbrich EJ, Jellus V, Nittka M, Pfirrmann CW. Reduction of metal artifacts in patients with total hip arthroplasty with sliceencoding metal artifact correction and view-angle tilting MR imaging. Radiology. 2012;265(1):204-14.

16. Jungmann PM, Agten CA, Pfirrmann CW, Sutter R. Advances in MRI around metal. J Magn Reson Imaging. 2017;46(4):972-91.

17. Khodarahmi I, Nittka M, Fritz J. Leaps in technology: advanced MR imaging after total hip arthroplasty. Semin Musculoskelet Radiol. 2017;21(5):604-15.

18. Muller GM, Lundin B, von Schewelov T, Muller MF, Ekberg O, Mansson S. Evaluation of metal artifacts in clinical MR images of patients with total hip arthroplasty using different metal artifactreducing sequences. Skelet Radiol. 2015;44(3):353-9.

19. Fritz J, Ahlawat S, Demehri S, Thawait GK, Raithel E, Gilson WD, et al. Compressed sensing SEMAC: 8-fold accelerated high resolution metal artifact reduction MRI of cobalt-chromium knee arthroplasty implants. Investig Radiol. 2016;51(10):666-76.

20. Jungmann PM, Bensler S, Zingg P, Fritz B, Pfirmann CW, Sutter R. Improved visualization of juxtaprosthetic tissue using metal artifact reduction magnetic resonance imaging: experimental and clinical optimization of compressed sensing SEMAC. Investig Radiol. 2019;54(1):23-31.

21. Talbot BS, Weinberg EP. MR imaging with metal-suppression sequences for evaluation of total joint arthroplasty. Radiographics. 2016;36(1):209-25. 
22. Fritz J, Lurie B, Miller TT, Potter HG. MR imaging of hip arthroplasty implants. Radiographics. 2014;34(4):E106-32.

23. Zanetti M, Bruder E, Romero J, Hodler J. Bone marrow edema pattern in osteoarthritic knees: correlation between MR imaging and histologic findings. Radiology. 2000;215(3):835-40.

24. Filli L, Jungmann PM, Zingg PO, Rudiger HA, Galley J, Sutter R, et al. MRI with state-of-the-art metal artifact reduction after total hip arthroplasty: periprosthetic findings in asymptomatic and symptomatic patients. Eur Radiol. 2019.

25. Kim CO, Dietrich TJ, Zingg PO, Dora C, Pfirrmann CWA, Sutter R. Arthroscopic hip surgery: frequency of postoperative MR arthrographic findings in asymptomatic and symptomatic patients. Radiology. 2017;283(3):779-88.

26. Bellamy N, Buchanan WW, Goldsmith CH, Campbell J, Stitt LW. Validation study of WOMAC: a health status instrument for measuring clinically important patient relevant outcomes to antirheumatic drug therapy in patients with osteoarthritis of the hip or knee. J Rheumatol. 1988;15(12):1833-40.

27. Ulbrich EJ, Sutter R, Aguiar RF, Nittka M, Pfirrmann CW. STIR sequence with increased receiver bandwidth of the inversion pulse for reduction of metallic artifacts. AJR Am J Roentgenol. 2012;199(6):W735-42.

28. Gruen TA, McNeice GM, Amstutz HC. "Modes of failure" of cemented stem-type femoral components: a radiographic analysis of loosening. Clin Orthop Relat Res. 1979;141:17-27.

29. DeLee JG, Charnley J. Radiological demarcation of cemented sockets in total hip replacement. Clin Orthop Relat Res. 1976;121:20-32.
30. Gorbachova T, Amber I, Beckmann NM, Bennett DL, Chang EY, Davis L, et al. Nomenclature of Subchondral nonneoplastic bone lesions. AJR Am J Roentgenol. 2019;213(5):963-82.

31. Kundel HL, Polansky M. Measurement of observer agreement. Radiology. 2003;228(2):303-8.

32. Mulcahy H, Chew FS. Current concepts of hip arthroplasty for radiologists: part 1, features and radiographic assessment. AJR Am J Roentgenol. 2012;199(3):559-69.

33. Sugimoto H, Hirose I, Miyaoka E, Fujita A, Kinebuchi Y, Yamamoto W, et al. Low-field-strength MR imaging of failed hip arthroplasty: association of femoral periprosthetic signal intensity with radiographic, surgical, and pathologic findings. Radiology. 2003;229(3):718-23.

34. Bosetti M, Masse A, Navone R, Cannas M. Biochemical and histological evaluation of human synovial-like membrane around failed total hip replacement prostheses during in vitro mechanical loading. J Mater Sci Mater Med. 2001;12(8):693-8.

35. Preutenborbeck M, Reuter J, Ferrari E. Quantitative characterisation of impaction events during femoral broaching in total hip arthroplasty. Med Eng Phys. 2020;76:13-9.

36. Connolly KP. Direct anterior total hip arthroplasty: literature review of variations in surgical technique. World Journal of Orthopedics. 2016;7(1):38.

Publisher's note Springer Nature remains neutral with regard to jurisdictional claims in published maps and institutional affiliations. 